
\title{
25 Research Soure \\ Effect of Licorice and Green Tea Gargle on Post- Extubation Sore Throat, Cough, and Hoarseness: A Triple-blind Clinical Trial
}

Hamid Karimi

Aja University of Medical Sciences

Nahid Rajai ( n.rajai22@yahoo.com)

Aja University of Medical Sciences

Zahra Farsi

Aja University of Medical Sciences

Parisa Hashemi

Emam Reza Hospital

Research Article

Keywords: Cough, Hoarseness, Sore throat, Green tea, Licorice

Posted Date: June 11th, 2021

DOI: https://doi.org/10.21203/rs.3.rs-611260/v1

License: (c) (i) This work is licensed under a Creative Commons Attribution 4.0 International License.

Read Full License 


\section{Abstract \\ Background}

Endotracheal extubation is associated with a high prevalence of complications such as sore throat, cough, and hoarseness. This study aimed to compare the effect of green tea and licorice gargle on sore throat, cough, and hoarseness after endotracheal extubation.

\section{Method:}

The study was designed as a randomized, triple-blind, controlled clinical trial. 102 patients who were candidates for elective surgery in two specialized hospitals in Tehran, Iran in 2020-2021, were randomly divided into licorice, green tea, and control (placebo) groups. The scores of sore throat, cough, and hoarseness of patients were assessed one hour after endotracheal extubation. After the gag reflex returned, patients were given $100 \mathrm{cc}$ of the prepared solutions to gargle for 30 seconds. The intervention was repeated two hours later. The scores of sore throat, cough, and hoarseness were assessed in the three groups, immediately after the first intervention and two hours after the second intervention.

\section{Result}

There was a significant difference between three groups, in posttest 1 and posttest 2 in terms of three variables $(P<0.0001)$. In addition, both licorice and green tea interventions had a high effect size on the decrease of the studied variables and there was no significant difference between these solutions $(P<$ 0.0167).

\section{Conclusion}

Both green tea and licorice solutions greatly reduced post-extubation complications. These results can be clinical evidence for the use of these two plants to prevent complications of endotracheal extubation.

\section{Trial registration:}

This study was registered in the Iranian Registry of Clinical Trials (IRCT) with the code “IRCT20190729044373N1" on 2019-12-27.

\section{Background}

Endotracheal intubation is performed during general anesthesia in order to protect the airway and prevent aspiration [1]. However, tracheal extubation after the anesthesia damages the airway [2] and can lead to 
complications such as sore throat, cough, and hoarseness with an incidence rate of $40-100 \%$ [3].

In fact, postoperative sore throat is a common and irritating issue [4] recognized by patients as the eighth unfavorable postoperative outcome [5].This complication often lasts for 72 hours after extubation, and $10 \%$ of cases have difficulty swallowing because of this problem [6]. In general, sore throat is caused by an inflammatory process due to throat and laryngeal and tracheal mucosal damage during intubation [7].

Post-extubation cough with a prevalence of $70 \%$ [8] is caused by damage to the larynx, trachea, and accumulation of secretions in the airway. Moreover, post-operative cough can result in the stretching of the sutures and intensified pain, especially in chest and abdominal surgeries [9].In addition, it can increase intracranial, eye, and abdominal pressure and risk of open-globe surgeries or abdominal aortic aneurysm [10]. Also, post-extubation hoarseness is caused by direct trauma to vocal cords during endotracheal intubation with a prevalence of $14.4-50 \%$ [11].

To date, various pharmacological and non-pharmacological methods have been used to reduce complications of endotracheal extubation, such as ketamine gargle, intravenous injection of Dexamethasone before entering the operating room [7],use of Lidocaine gel and K-Y gel [12] and application of Betamethasone gel on the endotracheal tube [13]. However, pharmacological medications have always been costly and associated with complications. Therefore, many have turned to complementary medicine owing to its low cost and fewer complications [14].One of the complementary medicine methods is phytotherapy, which uses the plant itself or its essential oil (aromatherapy) [15]. Moreover, researchers have used various phytotherapy methods to reduce extubation complications, such as green tea gargle [16], Licorice gargling [17], and Oucalyptus inhalation and reporting different results [2].

Green tea is sourced from Camellia Sinensis (L.) O. Kuntze and has antioxidant and anti-inflammatory activities [18] owing to the presence of 36 polyphenols, especially Catechins [19]. Green tea Catechins can be used to treat many inflammatory diseases (e.g., osteoarthritis and rheumatoid arthritis [20] and reduce allergic reactions to treatment) [21].

Licorice is the common name of Glycyrrhiza Glabra and a flowering plant of the bean family Fabaceae [22].The main constituents of the extract of licorice include Liquiritigenin, Hispaglabridins, Glycyrrhizic acid, Glycyrrhizin, Liquilitin, and Glabridin [23]. Notably, Liquilitin and Liquiritigenin have peripheral and central antitussive properties [24]. Glycyrrhizic acid can postpone inflammatory processes by inhibition of activities of Cyclooxygenase, formation of Prostaglandin, and platelet aggregation [25]. Glabridin also has antioxidant properties and can contribute to the improvement of the throat and tracheal mucosal injuries after laryngoscopy, endotracheal intubation, and endotracheal tube cuff pressure [26].

Limited studies have been performed to evaluate the effects of licorice and green tea on the decrease of post-extubation complications. For instance, Ibrahim and Anis reported that Ketamine and Licorice gargle equally reduced the incidence and severity of sore throat due to intubation [27]. In a study by Ariarifar et al., green tea gargle following extubation in patients undergoing open-heart surgery reduced sore throat 
and cough but had no significant impact on hoarseness [16]. Another study showed the positive effect of Licorice gargle on the decrease of sore throat and cough in patients after a Laminectomy [17].

Given the conflicting results obtained by different studies in terms of the effects of Licorice and green tea on post-extubation complications, and with regard to a lack of study on the comparison of the effects of the two plants of green tea and Licorice, the present study aimed to compare the impact of green tea and Licorice gargle on post-extubation complications of sore throat, cough and hoarseness.

\section{Method}

\section{Trial design}

This randomized, controlled, triple-blind clinical trial was performed in the operating rooms and surgical wards of two specialized hospitals in Tehran, Iran in 2020-2021.

\section{Study participants}

The study population included all patients who were candidates for elective surgery. Inclusion criteria included: patient and surgeon's consent to participate in the study, use of endotracheal tube for anesthesia, the age range of 18-65 years, ability to communicate and answer the questions, no sensitivity to the Licorice and green tea solutions, no airway infection, no surgery on the head and neck, ability to place the patient in a semi-sitting position to gargle the solution after surgery, no history of sore throat one week before the study and lack of diabetes.

Exclusion criteria included: Unwillingness of the patient or attending physician to cooperate with the researchers, intubation time of more than 30 seconds, a Mallampati score above two, endotracheal intubation more than once, and nausea and vomiting following starting the liquid diet.

\section{Sample size and randomization}

In this study, the sample size was estimated at 28 per group based on the mean and standard deviation of sore throat reported by Ghaleb et al [17]. and by considering a $95 \%$ confidence interval, $90 \%$ test power. However, considering a $20 \%$ attrition rate, 34 patients was allocated to each group.

$$
n=\frac{\left(z_{1-\alpha / 2}+z_{1-\beta}\right)^{2}\left(\sigma_{1}^{2}+\sigma_{2}^{2}\right)}{\left(\mu_{1}-\mu_{2}\right)^{2}}=\frac{(1.96+1.28)^{2}(0.48+0.93)}{(0.23-0.87)^{2}}=28.03
$$

In total, 102 patients, who were candidates of elective surgery, were selected by convenient sampling method based on inclusion criteria and allocated in three groups (licorice, green tea, and control) by use simple random allocation method. 
Using the medical record and the statements of the operating room nurses, the researcher examined the inclusion criteria and filled in the demographic and medical information questionnaire in the operating room. Demographic and medical characteristics of patients included: weight (kg), age (year), BMI $\left(\mathrm{kg} / \mathrm{m}^{2}\right)$, duration of surgery (minute), duration of intubation (minute), time trying to intubation (second).

The severity of sore throat in patients was measured using a numerical pain scale, which is a $10-\mathrm{cm}$ tool that shows a lack of pain at a score of 0 and maximum pain level at a score of 10 . This instrument has been used in various studies several times and its validity and reliability have been confirmed [14].

In addition, patients' cough and hoarseness were assessed by a four-point tool. Cough scoring based on the system included: No sore throat: 0 ; mild (less than a common cold): 1 ; moderate (similar to a common cold): 2; severe (more than a common cold): 3 . In addition, hoarseness scoring was carried out, as follows: No hoarseness: 0 ; mild (no hoarseness at the time of the interview but had it previously): 1; moderate (is only perceived by the patient): 2 ; severe (recognizable at the time of interview): 3 . Notably, the mentioned tools were frequently applied in previous studies and their validity and reliability were confirmed by test-retest $(r=0.6)$ and Mann-Whitney $U$ test $(P \leq 0.0004)[8,28]$.

\section{Interventions}

The Licorice used in this study was from Shirin Daroo Company with health license 15/11066. To prepare the Licorice solution, $50 \mathrm{~g}$ of Licorice root was brewed in 1 liter of water for 10 minutes. The green tea was also from Golestan Company with health license 16/19426. To prepare the green tea solution, 4.5 grams of green tea leaves brewed in $150 \mathrm{ml}$ of water for 10 minutes. The solutions prepared in opaque containers were named $\mathrm{A}, \mathrm{B}$, and $\mathrm{C}$, and the trained research assistants were blinded to the content of the containers. The three study groups were named with codes A, B, and C and one of the researchers kept the codes secret until the end of data analysis. Therefore, the research assistants, as well as patients and statistical analysts were blinded to the groups.

The magnitudes of sore throat, cough, and hoarseness of patients were assessed and recorded one hour after the surgery and endotracheal extubation and transfer of patients to the surgical ward. According to the routine of the ward, the fluid diet for patients was started as ordered by the physician following gag reflex return. At this stage, $100 \mathrm{cc}$ of solutions (Licorice, green tea, and plain water) at the right temperature for drinking $\left(25^{\circ} \mathrm{C}\right)$ were given to the patients to gargle for 30 seconds. The intervention was repeated two hours later. The magnitudes of sore throat, cough, and hoarseness of patients in all three groups were recorded immediately after the first intervention (posttest 1 ) and two hours after the second intervention (posttest 2).

\section{Statistical analysis}

Data analysis was performed in SPSS version 16 using One-sample Kolmogorov-Smirnov test (for testing the normal distribution of the data), mean, standard deviation, and frequency distribution table (for describing the data), One-way ANOVA (for comparison of demographic characteristics of patients in three 
groups), Kruskal-Wallis test and ANOVA (for comparison of cough, sore throat, and hoarseness in three stages of the study in the three groups), as well as the Friedman test (for intragroup comparison of variables). The P-value $<0.05$ was considered statistically significant. To compare the effect of green tea and Licorice solution on sore throat, cough and hoarseness of patients, Bonferroni correction was performed and $P<0.0671$ was considered as a significant level.

\section{Ethical considerations}

The study was approved by the ethics committee of Aja University of Medical Sciences (NO: IR.AJAUMS.REC.1398.216) and was registered on the Iranian Registry of Clinical Trials (ID: IRCT20190729044373N1). Authors adhered to the principles of the Helsinki Declaration, such as explaining the study objectives and methods to patients, voluntary participation in the study, no harm caused by the intervention, receiving a written informed consent, receiving permission from the attending physician, and ensuring the confidentiality terms regarding patients' information and the possibility of withdrawing from the study at any time.

\section{Results}

A total of 34 patients in each group participated and were followed up. None of the patients were excluded during the follow-up (Figure 1). The mean age of the patients was reported to be $34.89 \pm 12.03$ years (18-65 years). The patients' body mass index (BMI) was $26.09 \pm 2.36\left(19.48-34.10 \mathrm{~kg} / \mathrm{m}^{2}\right)$ and the duration of the surgery was $88.48 \pm 17.13$ minute. Moreover, the duration of endotracheal intubation was $14.92 \pm 3.36$ seconds, and the endotracheal tube size was $7.36 \pm 0.28 \mathrm{~mm}$. Post-extubation mean score of sore throat was estimated at $5.29 \pm 1.89$, whereas the mean scores of cough and hoarseness were $1.0 \pm 61.89$ and $1.70 \pm 0.88$, respectively. There was no significant difference between three groups regarding the demographic characteristics of patients $(P>0.05)$ (Table 1$)$.

\section{Sore throat variable}

ANOVA test results were indicative of no significant difference among the three groups regarding sore throat before the intervention ( $P>0.05$ ). Kruskal-Wallis test showed a significant difference between three groups at the post-test 1 and post-test 2 stages $(P<0.0001)$, in a way that the lowest sore throat scores were obtained by the Licorice group. The Licorice intervention had a high effect size $(E S)$ on the sore throat at the post-test $1(E S=0.85)$ and post-test 2 stages $(E S=1.5)$. In addition, the green tea intervention had a high effect size on at the post-test $1(E S=0.76)$ and post-test $2(E S=1.45)$ stages. Also, the Friedman test showed a significant difference between the study stages in each group $(P<0.0001)$ (Table 2).

\section{Cough variable}

Kruskal-Wallis test showed no significant difference between three groups regarding the cough before the intervention ( $P>0.05)$. However, post-test 1 and post-test 2 results, demonstrated a significant difference 
among the three groups $(P<0.0001)$. The lowest cough score was observed in the green tea and Licorice groups at the post-test 1 and post-test 2 stages, respectively. Licorice intervention had a high effect size on the reducing the cough at the post-test $1(E S=0.73)$ and post-test $2(E S=1.24)$ stages. Similarly, the effect size of green tea intervention was high in post-test $1(E S=0.94)$ and post-test $2(E S=1.2)$ stages. Also, the Friedman test showed a significant difference between the study stages in each group $(P<$ 0.0001) (Table 3).

\section{Hoarseness variable}

Kruskal-Wallis test showed no significant difference between three groups regarding hoarseness before the intervention ( $P>0.05)$. Nevertheless, a significant difference was reported among the three groups at the post-test 1 and post-test 2 stages $(P<0.0001)$. The lowest hoarseness score was observed in the green tea group at both stages after intervention. However, Licorice intervention had a high effect size on the reducing the hoarseness at the post-test $1(E S=1.03)$ and post-test $2(E S=0.96)$ stages. Similarly, the effect size of green tea intervention was high in post-test $1(E S=0.7)$ and post-test $2(E S=1.29)$ stages. Also, the Friedman test showed a significant difference between the study stages in each group $(P<$ 0.0001) (Table 4).

According to Mann-Whitney $U$ results, no significant difference was observed between the two intervention groups (licorice and green tea) during the study stages regarding the variables of sore throat, cough, and hoarseness $(P<0.0167)$. It is notable that no side effect due to the use of the solutions was reported in this study.

\section{Discussion}

Before the intervention, the groups were homogenous in terms of demographic characteristics, sore throat, cough, and hoarseness. After the first and second stages of the intervention, the cough, sore throat and hoarseness scores were significantly lower in the two intervention groups, compared to the control group. In addition, the results showed that Licorice and green tea gargle extremely reduced the studied variables and no significant difference was observed between these two groups, in this respect. Moreover, intragroup comparison demonstrated a significant difference between the three groups in all study stages. These results could indicate the effectiveness of the intervention and passage of time on the decrease of variables. However, this did not apply to the control group regarding the hoarseness variable since it increased after the second intervention stage.

In general, Licorice and green tea gargle had similar impacts on the decrease of post-extubation complications. A literature search revealed a lack of study on the effect of the two mentioned solutions on the decrease of post-extubation complications. However, some studies found in this area separately assessed the effects of the two interventions in different ways, and their results were consistent with our findings. For instance, Gupta et al. evaluated the effect of Licorice lozenges (intervention group) and sugar candy (control group) on cough, sore throat, and hoarseness of 100 smokers presenting for elective surgery, after anesthesia. According to the results, Licorice lozenges reduced all three variables [29]. 
Ruetzler et al. performed a study on 236 patients having elective thoracic surgery to evaluate the effect of preoperative gargling with Licorice and sugar water. The result showed Licorice group compared with sugar water group, experienced 1.7 times $(95 \% C l, 1.1-2.7)$ lower coughing $(P<0.001)$ and sore throat score (RR [95\% Cl: 0.53 [0.32-0.88], $(P=0.003)$ [4].

According to Ibrahim and Anis, pre-operation Licorice and Ketamine gargling significantly decreased the incidence and severity of postoperative sore throat. However, no significant difference was observed between the ketamine and licorice groups [27]. In another study by Ghaleb et al., gargling $500 \mathrm{mg}$ of Licorice diluted in $30 \mathrm{cc}$ of water five minutes before induction significantly decreased sore throat $(P=$ $0.0002)$ and improve swallowing $(P=0.001)$ in patients [17]. Kuriyama et al. evaluated the effect of postoperative topical application of Licorice on sore throat after surgery, in a meta-analysis and systematic review. According to the results, Licorice reduced the prevalence (risk ratio, $0.44 ; 95 \%$ confidence interval $(C l), 0.28-0.69 ; P<0.001$ ) and severity (standardized mean difference, $-0.69 ; 95 \% C l,-0.96,-0.43 ; P<$ 0.001 ) of sore throat [30].

Regarding the effect of green tea, Jafari et al. reported that gargling $30 \mathrm{cc}$ of the solution after an openheart surgery reduced sore throat in patients 12 hours $(P=0.047)$ and 24 hours $(P<0.001)$ after the intervention [31]. In a study by Ariaei et al., gargling with green tea solution four times a day after anesthesia by patients undergoing open-heart surgery reduced sore throat, 12 hours after the intervention. However, no significant change was observed in the hoarseness variable in three stages [16]. This lack of consistency might be due to the long surgery period (8-10 hours), compared to the present study. In a study by Liu et al., daily drinking of green tea after a robotic or laparoscopic subtotal gastrectomy reduced post-operative pain and complications on the first-fourth post-operative days [32]. In fact, green tea's effect on the decrease of postoperative sore throat is related to its anti-bacterial, anti-inflammatory, and anti-oxidative properties [33].The anti-inflammatory properties of this substance are such that its effectiveness in healing surgical wounds has been confirmed [34].

\section{Conclusion}

In the present study, both green tea and Licorice substances with high effect size reduced endotracheal intubation outcomes (cough, sore throat, and hoarseness) after surgery, which is in line with the results of several studies. With regard to the simple use, cost-effectiveness, and low risk of Licorice and green tea gargle, it is recommended that these solutions be used to reduce post-extubation complications. It is also suggested that further studies be carried out to compare the effect of these substances with pharmacological treatments.

\section{Declarations}

\section{Acknowledgments}

We would like to thank all the people who helped us in this project. 


\section{Authors' contributions}

HK, searched literature, wrote manuscripts, prepared materials needed for intervention, performed intervention, collected data, and managed data with scientific support from NR and ZF and with help of $\mathrm{PH}$. This project was supervised by NR and ZF performed statistical analysis.

\section{Funding}

This study was conducted with the financial support of the Aja University of Medical Sciences.

\section{Availability of data and materials}

The raw data collected in this study are available at the request of the corresponding author.

\section{Declarations}

\section{Ethics approval and consent to participate}

The study was approved by the ethics committee of Aja University of Medical Sciences (NO: IR.AJAUMS.REC.1398.216) and was registered on the Iranian Registry of Clinical Trials (ID: IRCT20190729044373N1). Authors adhered to the principles of the Helsinki Declaration, such as receiving a written informed consent from participant and permission from the attending physician.

\section{Consent for publication}

Not applicable.

\section{Competing interests}

There is no Competing interest in this study.

\section{References}

1. Hassan Mohammadipour A, Maarouf Ansari K, Khosro K, Nasser G, Afsaneh K. Effect of single dose of pregabalin on post tracheal intubation sore throat after general anesthesia. Archives of Anesthesiology and Critical Care. 2019; 5(3): 95-98. https://doi.org/10.18502/aacc.v5i3.1210

2. Zare S, Bagheri-Nesami M, Jafari H, Yazdani Charati J, Habibi V. Effect of eucalyptus vapor on hoarseness and sore throat following intubation after coronary artery bypass surgery. Journal of Mazandaran University of Medical Sciences. 2018; 27(158):5666. 
3. Banihashem N, Alijanpour E, Hasannasab B, Zarei A. Prophylactic effects of lidocaine or beclomethasone spray on post-operative sore throat and cough after orotracheal intubation. Iran J Otorhinolaryngol. 2015; 27(80):179. Doi:10.22038/IJORL.2015.3822

4. Ruetzler K, Fleck M, Nabecker S, Pinter K, Landskron G, Lassnigg A, et al. A randomized, double-blind comparison of licorice versus sugar-water gargle for prevention of postoperative sore throat and postextubation coughing. Anesth Analg. 2013;117(3):61421.

5. Rajan S, Malayil GJ, Varghese R, Kumar L. Comparison of usefulness of ketamine and magnesium sulfate nebulizations for attenuating postoperative sore throat, hoarseness of voice, and cough. Anesth Essays Res. 2017; 11(2):287293. Doi:10.1213/ANE.0b013e318299a650.

6. Kalil DM, Silvestro LS, Austin PN. Novel preoperative pharmacologic methods of preventing postoperative sore throat due to tracheal intubation. AANA J. 2014; 82(3):188-97.

7. Manandhar S, Manandhar K, Khakrel S. Efficacy of dexamethasone in reducing the incidence of postoperative sore throat: a double blind randomized study. Journal of Patan Academy of Health Sciences. 2018; 5(1):10-5. Doi:10.3126/JPAHS.V5I1.24034

8. Navarro LH, Lima RM, Aguiar AS, Braz JR, Carness JM, Módolo NS. The effect of intracuff alkalinized 2\% lidocaine on emergence coughing, sore throat, and hoarseness in smokers. Rev Assoc Med Bras (1992). 2012;58(2):248-53.

9. Nasorollahi MS, Rejeh N, Heravi-Karimooi M, Sarlak A. Examining the effect of humidifier therapy on hoarseness and coughing following endotracheal extubation in the elderly after undergoing coronary artery bypass surgery. Journal of Critical Care Nursing. 2018;11(4):44-52. 
10. Lin W, Sun J, Fu S. A small dose of remifentanil pretreatment suppresses sufentanilinduced cough during general anesthesia induction: a randomized, double-blind, placebocontrolled trial. BMC Anesthesiol. 2019;19(1):164.

11. Feierabend RH, Shahram MN. Hoarseness in adults. Am Fam Physician. 2009; 80(4):363-70.

12. Doukumo D, Faponle A, Bolaji B, Adenekan A, Olateju S. Effects of lidocaine and ky jellies on sore throat, cough, and hoarseness following endotracheal anaesthesia. J West Afr Coll Surg. 2011; 1(3):44-61

13. Kajal K, Dharmu D, Bhukkal I, Yaddanapudi S, Soni SL, Kumar M, et al. Comparison of three different methods of attenuating postoperative sore throat, cough, and hoarseness of voice in patients undergoing tracheal Intubation. Anesth Essays Res. 2019; 13(3):572-6. Doi:10.4103/aer.AER_61_19.

14. Nasiri M, Farsi Z. Effect of light pressure stroking massage with sesame (Sesamum indicum L.) oil on alleviating acute traumatic limbs pain: A triple-blind controlled trial in emergency department. Complement Ther Med. 2017; 32:418. Doi:10.1016/j.ctim.2017.03.004.

15. Teymouri F, Rajai N, Farsi Z, Pourmirzai M. The effects of inhaling Lavender fragrance on stress and anxiety during sheath take out in patients after coronary $\begin{array}{lllll}\text { angiography. Journal of } & \text { Medicinal }\end{array}$

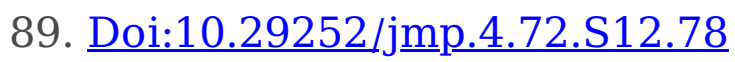

16. Aryaeefar MR, Jafari H, Yazdani-Charati J, Soleimani A. Green tea gargling effect on cough \& hoarseness after coronary artery bypass graft. Glob J Health Sci. 2015; 7(5):266-71.

17. Ghaleb MA, Falatah S, Al-Amoudi FA. The efficacy of licorice gargle for attenuating postoperative sore throat. Am J Res Commun. 2013; 1(11):37994. Doi:10.5539/gjhs.v7n5 $\underline{\text { 266 }}$ 
18. Suzuki T, Pervin M, Goto S, Isemura M, Nakamura Y. Beneficial effects of tea and the green tea catechin epigallocatechin-3-gallate on obesity. Molecules. 2016; 21(10):1305. Doi:10.3390/molecules21101305

19. Perva-Uzunalic A, Skerget M, Knez Z, Weinreich B, Otto F, Gruner S. Extraction of active ingredients from green tea (Camellia sinensis): Extraction efficiency of major catechins and caffeine. Food Chemistry. 2006; 96(4):597-605.

20. Yun HJ, Yoo WH, Han MK, Lee YR, Kim J-S, Lee SI. Epigallocatechin-3-gallate suppresses TNF- $\alpha$-induced production of MMP-1 and -3 in rheumatoid arthritis synovial fibroblasts. Rheumatol In. 2008; 29(1):23-9. Doi:10.1007/s00296-008-0597-5.

21. Bani D, Giannini L, Ciampa A, Masini E, Suzuki Y, Menegazzi M, et al. Epigallocatechin-3-Gallate reduces allergen-Induced asthma-Like reaction in sensitized Guinea pigs. J Pharmacol Exp Ther. 2006; 317:1002-11. Doi:10.1007/s00296-008-0597-5.

22. Kuroda M, Mimaki Y, Honda S, Tanaka H, Yokota S, Mae T. Phenolics from Glycyrrhiza glabra roots and their PPAR-gamma ligand-binding activity. Bioorg Med Chem. 2010; 18(2):962-70. Doi:10.1016/j.bmc.2009.11.027.

23. Glycyrrhiza glabra. Monograph. Altern Med Rev. 2005;10(3):230-7.

24. Kamei J, Nakamura R, Ichiki H, Kubo M. Antitussive principles of Glycyrrhizae radix, a main component of the Kampo preparations Bakumondo-to (Mai-men-dong-tang). Eur J Pharmacol. 2003; 469:159-63. Doi:10.1016/s0014-2999(스) $\underline{\text { 01728-x. }}$.

25. Izzo AA, Di Carlo G, Borrelli F, Ernst E. Cardiovascular pharmacotherapy and herbal medicines: the risk of drug interaction. Int J Cardiol. 2005; 98:114.Doi:10.1016/j.ijcard.2003.06.039

26. Chin YW, Jung HA, Liu Y, Su BN, Castoro JA, Keller WJ, et al. Anti-oxidant constituents of the roots and stolons of licorice (Glycyrrhiza glabra). J Agric Food Chem. 2007; 55: 4691-7. Doi:10.1021/jf0703553 
27. Ibrahim A, Anis S. Licorice versus ketamine gargles for postoperative sore throat due to insertion of a double-lumen endobronchial tube. Egypt $\mathrm{J}$ Cardiothorac Anesthes.2016; 10(3):45-9. Doi:2016/10/3/45/200283

28. Shaaban AR, Kamal SM. Comparison between betamethasone gel applied over endotracheal tube and ketamine gargle for attenuating postoperative sore throat, cough and hoarseness of voice. Middle East J Anaesthesiol. 2012; 21(4):513-9.

29. Gupta D, Agrawal S, Sharma JP. Effect of preoperative Licorice lozenges on incidence of postextubation cough and sore throat in smokers undergoing general anesthesia and endotracheal intubation. Middle East J Anaesthesiol. 2013; 22(2):173-178.

30. Kuriyama A, Maeda H. Topical application of licorice for prevention of postoperative sore throat in adults: A systematic review and meta-analysis. J Clin Anesth. 2019; 54:25-32. Doi:10.1016/j.jclinane.2018.10.025.

31. Jafari H, Ariaeifar MR, Charati JY, Soleimani A, Formi EN. The effect of green tea gargle solution on sore throat after coronary artery bypass grafting: A randomized clinical trial. Anesth Pain Med. 2016; 9; 6 (3):e32108. Doi:10.5812/aapm.32108.

32. Liu D, Jing $X$, Cao Sh, Liu $X$, Tan $X$, Jiang H, et al. Impact of drinking Chinese green tea on postoperative short outcomes for gastric cancer: a randomized controlled trial. Eur J Clin Nutr. 2;021Online ahead of print.

33. Reygaert WC. Green tea Catechins: their use in treating and preventing infectious diseases. Biomed Res Int. 2018; 2018: 9105261. Doi:10.1155/2018/9105261.

34. Asadi SY, Parsaei P, Karimi M, Ezzati S, Zamiri A, Mohammadizadeh F, et al. Effect of green tea (Camellia sinensis) extract on healing process of surgical wounds in rat. Int J Surg. 2018; 11(4):332-7. https://doi.org/10.1016/j.ijsu.2013.02.014

\section{Tables}

Table 1: Comparison of demographic characteristics of patients in three groups 


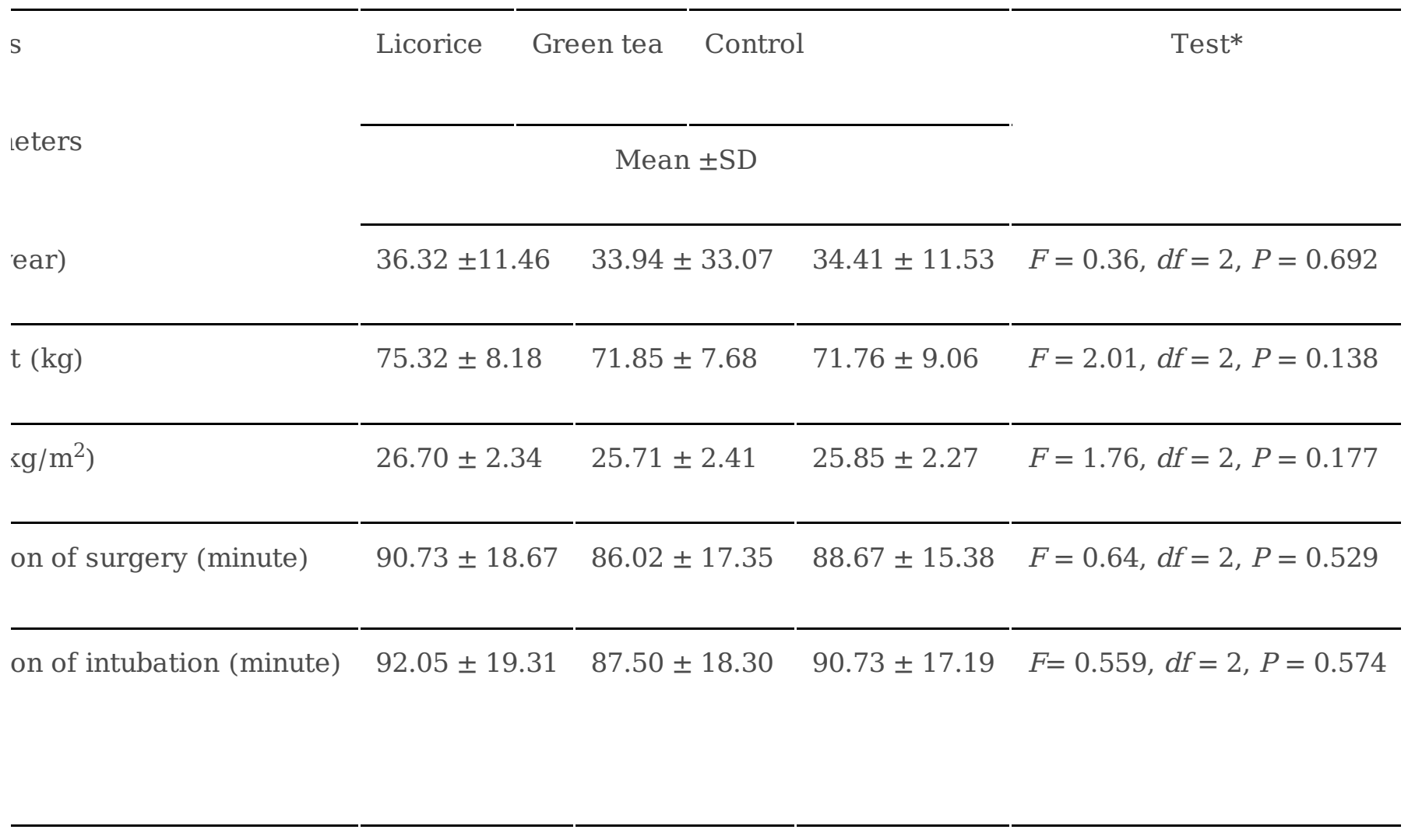

\section{*One Way ANOVA}

Table 2: Comparison of sore throat across three study groups in three stage of study 


s $\quad$ Licorice $\quad$ Green tea $\quad$ Test

Mean \pm SD

\begin{tabular}{|c|c|c|c|c|}
\hline st & $5.82 \pm 1.38$ & $5.17 \pm 1.60$ & $4.88 \pm 2.44$ & $F^{\S}=2.259 d f=2, P=0.110$ \\
\hline sst 1 & $2.44 \pm 1.10$ & $2.58 \pm 1.20$ & $3.76 \pm 1.55$ & Value $^{\text {ब }}=17.05 \mathrm{df}=2, P<0.0001$ \\
\hline sst 2 & $1.08 \pm 1.26$ & $1.20 \pm 1.03$ & $3.26 \pm 1.42$ & $\begin{array}{l}\text { Value }{ }^{\pi}=38.27 d f=2, P< \\
0.0001\end{array}$ \\
\hline
\end{tabular}

value $=65.78 \quad$ Value $=66.51$
$d f=2, \mathrm{P}<d f=2, \mathrm{P}<d f=2, P<0.0001$
0.0001
0.0001

Post-test 1: Immediately after the first stage of intervention, Post-test 2: Two hours after the second stage of intervention; ${ }^{\S}$ ANOVA test; ${ }^{\text {ๆ }}$ Kruskal Wallis test; $\mathrm{P}<0.05$.

Table 3: Comparison of cough across three study groups in three stage of study. 


$\overline{\text { Licorice }}$ Green tea $\quad \overline{\text { Control Test* }}$

Mean \pm SD

\begin{tabular}{|c|c|c|c|c|}
\hline -test & $1.82 \pm 0.86$ & $1.46 \pm 0.92$ & $1.58 \pm 0.85$ & Value $=3.33 d f=2, P=0.188$ \\
\hline t-test 1 & $0.67 \pm 0.36$ & $0.52 \pm 0.70$ & $1.20 \pm 0.72$ & Value $=15.33 d f=2, P<0.0001$ \\
\hline t-test 2 & $0.14 \pm 0.43$ & $0.17 \pm 0.38$ & $1.00 \pm 0.69$ & Value $=39.10, d f=2, P<0.0001$ \\
\hline
\end{tabular}

ədman test $\quad$ Value $=57.78 \quad$ Value $=49.08 \quad$ Value $=9.53$

$d f=2, P<0.0001 \quad d f=2, P<0.0001 \quad d f=2, P<0.0001$

Post-test 1: Immediately after the first stage of intervention, Post-test 2: Two hours after the second stage of intervention; ${ }^{*}$ Kruskal Wallis Test; $\mathrm{P}<0.05$.

Table 4: Comparison of hoarseness across three study groups in three stage of study. 


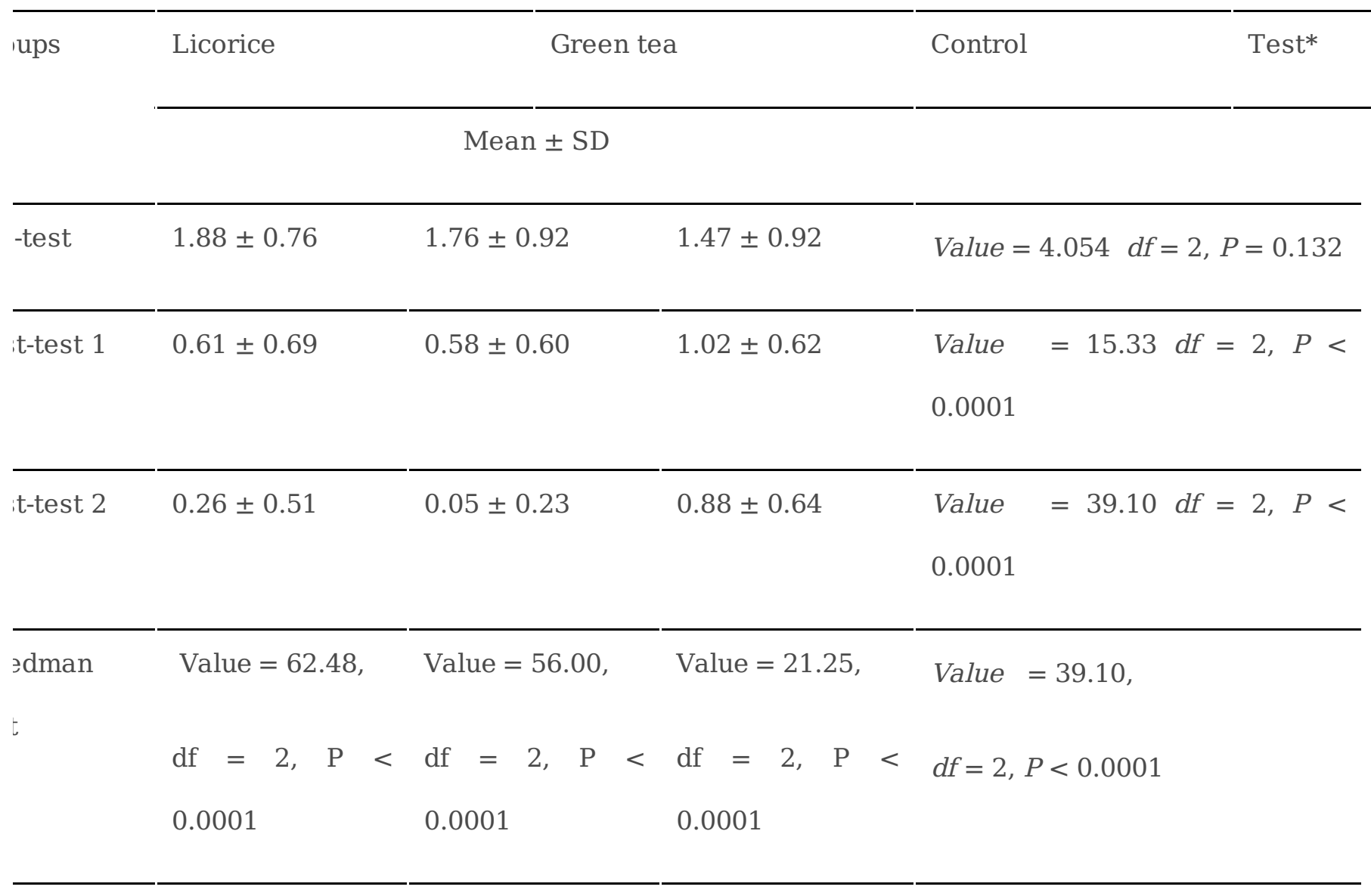

Post-test 1: Immediately after the first stage of intervention, Post-test 2: Two hours after the second stage of intervention; ${ }^{*}$ Kruskal Wallis Test; $\mathrm{P}<0.05$.

\section{Figures}




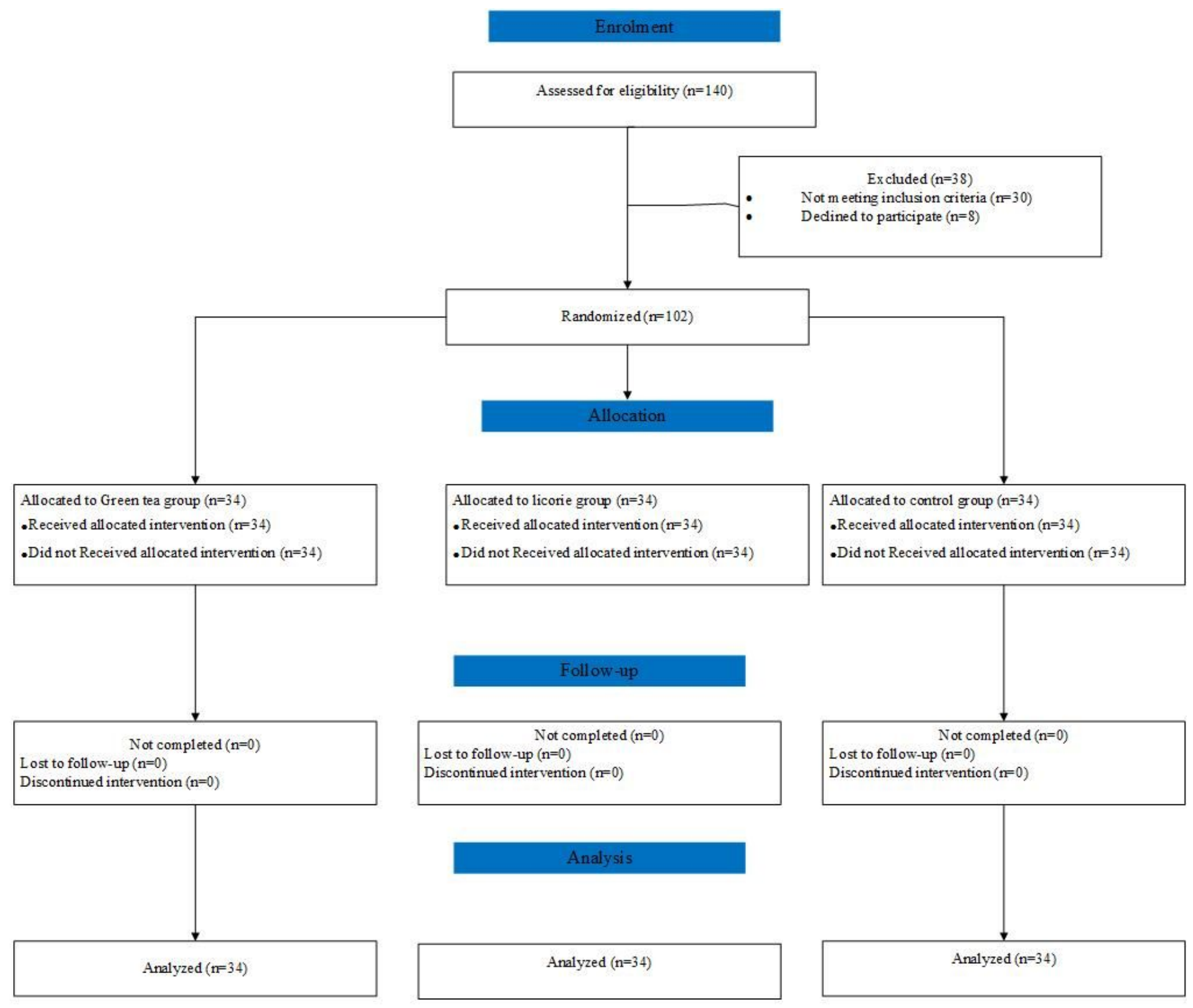

Figure 1: Flow chart of random allocation in three groups of study (According CONSORT diagram 2010)

\section{Figure 1}

Flow chart of random allocation of groups 